\title{
Lipopolysaccharide challenge of the mammary gland in bovine induced a transient glandular shift to anaerobic metabolism
}

\author{
N. Silanikove, ${ }^{\star 1}$ A. Rauch-Cohen, ${ }^{*}$ F. Shapiro, ${ }^{*}$ S. Blum,† A. Arieli, $\neq$ and G. Leitner† \\ *Biology of Lactation Laboratory, Institute of Animal Science, the Volcani Center, POB 6, Bet Dagan 50250, Israel \\ †Kimaron Veterinary Institute, National Mastitis Center, POB 12, Bet Dagan 50250, Israel \\ †Department of Animal Science, Faculty of Agricultural, Food and Environmental Sciences, Hebrew University of Jerusalem, \\ Rehovot 76-100, Israel
}

\begin{abstract}
Support of milk production in modern dairy cows demands a large proportion of its own metabolic resources, such as glucose, which might be required under stressful situations. The aim of the experiment was to test the hypothesis that acute immune stress shifts oxidative metabolism to glycolysis. Two mammary quarters in 6 Holstein cows were infused with lipopolysaccharide (LPS), whereas the 2 counter quarters served as controls to the treatment. An additional 6 cows were infused with saline and served as running controls. The LPS challenge induced dramatic transient increases in milk lactate (75-fold) and malate (11-fold) concentrations (both markers of glycolysis) at $24 \mathrm{~h}$ posttreatment. No significant changes in lactate and malate concentrations were recorded in control quarters and control animals, indicating that the effect of LPS was restricted to the treated gland. The LPS challenge induced a dramatic transient decrease in milk yield, and lactose and citrate (a marker of mitochondrial metabolism) secretion at $24 \mathrm{~h}$ posttreatment. The kinetics were inversely proportional to those of lactate and malate concentrations. Thus, our data suggest that LPS challenge induces acute conversion of epithelial cell metabolism from principally mitochondrial-oxidative to principally cytosolic (glycolytic), which allows the diversion of metabolic resources normally used to synthesize milk to support the immune system. An in vitro bacterial growth test showed that concentrations of lactate, malate, and lactose equivalent to those found in the in vivo experiment delayed and reduced the growth of a pathogenic Escherichia coli strain, suggesting that they play a role in diminution of bacterial multiplication in the mammary gland.
\end{abstract}

Key words: stress response, mammary gland, lipopolysaccharide (LPS), glycolysis

Received December 14, 2010.

Accepted May 24, 2011.

${ }^{1}$ Corresponding author: nsilanik@agri.huji.ac.il

\section{INTRODUCTION}

Milk yield in the last 4 decades has increased tremendously because of selection of dairy cows. Today, milk volumes range from 40 to $70 \mathrm{~L} / \mathrm{d}$ in countries such as Israel and the United States, compared with $10 \mathrm{~L} / \mathrm{d}$ or less before selection (Kadzere et al., 2002). The production of milk at these levels extracts 70 to $80 \%$ of wholeanimal metabolic energy intake (Kadzere et al., 2002). This high metabolic rate is associated with a similar drain of whole-body glucose production, which is used mainly to produce lactose (Qiao et al., 2005). Thus, essential metabolic resources such as glucose might be in short supply when the animal faces an acute stressful situation.

Exposing animals to acute stress such as heat stress and dehydration necessitates the inducement of a regulatory mechanism that rapidly down-regulates milk secretion to survive the challenge imposed by such stress (Silanikove, 1994). A milk-borne negative feedback system that increases the potential for survival in response to stress was described by our group (Silanikove et al., 2000, 2006, 2009). This system comprises an endogenous milk enzymatic system, plasminogen activator-plasminogen-plasmin, and plasmin-derived $\beta$-casein fragment (f) (1-28) from $\beta$-CN, which acts as the negative control signal by closing potassium channels on the apical membrane of the epithelial cells of the mammary gland. Milk stasis intensely activates this system, leading to precipitously low levels of milk secretion and inducing involution of the mammary gland. Eventually, signals from a regulatory system should be translated into a metabolic mechanism; in this case, a metabolic system that reduces synthesis and secretion of milk. This mechanism should be very effective because considerable (30 to 50\%) and large (>70\%) reductions in milk secretion were measured within $12 \mathrm{~h}$ of activation of the above-described negative feedback system under stress (Silanikove et al., 2000, 2006) and milk stasis (Shamay et al., 2002, 2003).

As blood flow and metabolite extraction by the mammary gland are autoregulated according to the 
metabolic activity of the organ (Cherepanov et al., 2000), we presupposed that reduction in the metabolic activity of the mammary epithelia is responsible for the reduction in milk synthesis and secretion. A rapid shift of epithelial cell metabolism from mitochondrial oxidative metabolism to cytosolic anaerobic glycolysis ought to be associated with drastic reductions in ATP yield from the cells, and therefore, can explain that presupposition.

L-Lactic acid (lactate) is the main product of glycolysis in the cell cytosol (extra-mitochondrial metabolism) in eukaryotes, including mammals. Citric acid starts the respiratory metabolism in the Krebs cycle (citric acid cycle) in the mitochondrion. The source of lactate and citrate in milk is the mammal's alveolar epithelial cells. Citrate is secreted into the milk along with lactose via the Golgi vesicles, and its concentration in milk reflects changes in intracellular citrate concentrations (Linzell et al., 1976; Zulak and Keenan, 1983).

A common feature of clinical and subclinical mastitis is reduction in milk lactose concentration (LindmarkMansson et al., 2006). The reduction in lactose secretion in subclinically infected quarters occurs without evidence of tight junction disruption (Leitner et al., 2011). Thus, this reduction reflects a reduction in lactose synthesis and secretion rather than its loss from the mammary gland due to leakage into the blood. In addition, subclinical mastitis is associated with increased content of L-lactate in milk (Davis et al., 2004; Lindmark-Mansson et al., 2006). Lactic acid bacteria can produce D-lactate (Shapiro and Silanikove, 2010). As eukaryotes produce exclusively the L-stereoisomer of lactate, the increase in the concentration of L-lactate indicates that the source of the acid is the host cells rather than fermentation of lactose by invading lactic acid-producing bacteria. Bovine milk (and that of some other mammalian species) contains characteristically low levels of L-lactate $(\sim 300 \mu M)$ and D-lactate $(\sim 10$ $\mu M$; Shapiro and Silanikove, 2010) and relatively high levels of citrate (9-15 mM; Linzell et al., 1976; Zulak and Keenan, 1983). The physiological and immunological significance of reduction in lactose concentration and increased lactate concentration in milk under inflammatory conditions is poorly understood; however, these changes are consistent with the stated hypothesis that the shift to anaerobic metabolism is a mechanism for saving energy.

Challenge of the mammary gland with LPS is generally accepted as an appropriate model for studying the effect of acute immunological stress. Lipopolysaccharide, the foremost glycolipid outer membrane constituent of gram-negative bacteria, potently stimulates immune cells by binding cell-surface toll-like receptor 4 and activating transcription factors and protein ki- nases, such as nuclear factor- $\kappa \mathrm{B}$ and p38 kinase, resulting in an increased production of proinflammatory cytokines and overexpression of cell adhesion molecules and matrix-degrading enzymes (Heumann and Roger, 2002). Exposure of a tissue to LPS induces rapid inflammation, which imitates, to a large extent, the inflammatory response induced by Escherichia coli infection. Therefore, LPS challenge is a common model to study the inflammatory response induced by pathogenic $E$. coli as well as its endotoxins in the mammary gland and other tissues (Rainard and Riollet, 2006).

The aim of the present experiment was to test the hypothesis that LPS challenge of the mammary gland shifts epithelial cell metabolism from principally oxidative to glycolytic by following the secretion of key metabolites such as lactose, lactate, malate, citrate, and urea that should reflect such changes.

\section{MATERIALS AND METHODS}

\section{Ethics}

All protocols were approved by the Institutional Animal Care Committee of the Agricultural Research Organization (ARO), which is the legitimate body for such authorizations in Israel.

\section{Experimental Design}

Twelve Israeli Holstein heifers, yielding $33.2 \pm 3.1$ $\mathrm{L}$ of milk/d, in their first lactation were divided into 2 groups (treatments), experimental and control, of 6 cows each, on the basis of similar milk yield (MY). The cows had low leukocyte content, as indicated by low SCC $(<30,000$ cells $/ \mathrm{mL})$ and no bacterial findings (Leitner et al., 2006).

One week before the start of the experiment, the 12 cows were moved to a separate yard that provided $10 \mathrm{~m}^{2}$ of shaded slatted floor. Before and during the experiment the cows were fed a typical Israeli TMR (17\% protein) containing 65\% concentrate and 35\% forage, which was offered ad libitum in mangers; water was available at all times. The experiment was carried out during November under a natural lighting regimen, with typical noon temperatures of $24^{\circ} \mathrm{C}$ and night temperatures of $12^{\circ} \mathrm{C}$, which are considered favorable for cow welfare (Silanikove, 2000). The cows were milked thrice daily $(0530,1230$, and $2130 \mathrm{~h}$ ) and individual MY and other milk parameters were recorded automatically (AfiFarm Herd Management Software, S.A.E. Afikim, Kibbutz Afikim, Israel).

All experimental procedures were carried out during the noon milking. During the $4 \mathrm{~d}$ of the study $(-24 \mathrm{~h}$, $0 \mathrm{~h},+24 \mathrm{~h},+48 \mathrm{~h}$, and $+72 \mathrm{~h}$, where $0 \mathrm{~h}$ refers to day 
of infusion), every quarter of each cow was separately milked into individual containers, and milk samples were taken after recording MY. In the control cows, 2 mammary quarters, one front and one rear, were infused with $10 \mathrm{~mL}$ of sterile nonpyrogenic saline solution (Teva Pharmaceutical Industries Ltd., Petach Tikva, Israel; r-Con). The 2 counter quarters (c-Con) served as controls to the procedure. In the experimental cows, 2 mammary quarters, one front and one rear, were infused with LPS; $10 \mu \mathrm{g}$ of LPS (E. coli O55B5; Sigma Chemical Co., St. Louis, MO) dissolved in $10 \mathrm{~mL}$ of sterile nonpyrogenic saline (e-LPS), whereas the 2 counter quarters served as controls to the treatment (c-LPS). Intramammary infusion was injected with a special applicator following careful sterile cleaning of the teat. Milk yield was discarded for $7 \mathrm{~d}$ following the infusion.

\section{Analytical Procedures}

One subset of samples was sent to a central laboratory for the determination of fat, protein, lactose, and urea (Leitner et al., 2006). The amount of milk components secreted and the concentration of a particular component at each point of time were calculated from the MY. Additional subsets of milk samples were defatted under cold conditions (Silanikove and Shapiro, 2007) and analyzed for lactose, L-lactate, D-lactate (Shapiro and Silanikove, 2011), malate, and citrate by enzymatic reactions coupled to formation of a fluorochromophore (Shapiro and Silanikove, 2011).

\section{Statistical Analysis}

The data sets of this study were analyzed using repeated-measures analysis (PROC MIXED) modeling correlated residuals within cow (SAS Institute, 2002) as described previously (Shamay et al., 2003). Briefly, the analysis focused on the effects of treatment, day, and treatment $\times$ day interactions. The effect of DIM was not significant $(P>0.25)$ and, therefore, was not included in the analyses presented.

The model used was

$$
Y_{i j k m}=\mu+C_{i}+T_{j}+T_{j} D_{k}+Q_{m}\left(T_{j} C_{i}\right)+e_{i j k m},
$$

where $Y_{i j k m}$ is the variable within cow, treatment, quarter, and day; $\mu$ is the variable average; $C_{i}$ is the cow class effect; $T_{j}$ is the treatment class effect; $D_{k}$ is the day class effect; $T_{j} D_{k}$ is the treatment $\times$ day interaction effect; $Q_{m}\left(T_{j} C_{i}\right)$ is the quarter within cow treatment error term for treatment effect; and $e_{i j k m}$ is the residual error.
No differences were found between the results of $r-$ Con and c-Con: therefore, their results were pooled and presented as c-Con.

\section{In Vitro Test}

The kinetics of growth of pathogenic E. coli $\mathrm{P} 4$ strain (Bramley, 1976) were evaluated in different media as described by Blum et al. (2008). Briefly, bacteria were cultured in nutrient agar with $5 \%$ washed sheep erythrocytes. Prior to the assay, bacteria were grown in peptone water for $4 \mathrm{~h}$. Bacterial concentration was adjusted with peptone water to $1 \times 10^{8} \mathrm{cfu} / \mathrm{mL}$ using a previously established standard curve of optical density $x$ bacterial counts, and finally adjusted to a working concentration of $1 \times 10^{5} \mathrm{cfu} / \mathrm{mL}$. The following media were aseptically prepared: peptone water, peptone water with 0,3 , and $5 \%$ lactose, and a mixture of lactic acid $(15 \mathrm{mM})$ and malic acid $(5 \mathrm{mM})$. All media were filter-sterilized before the experiment. Growth was tested in the following media: peptone water, peptone water with 0,3 , or $5 \%$ lactose, peptone water with $5 \%$ lactose, $15 \mathrm{~m} M$ lactate, and $5 \mathrm{~m} M$ malate. In a 96-well, round-bottomed microplate, $200 \mu \mathrm{L}$ of each medium was aseptically distributed and inoculated with $20 \mu \mathrm{L}$ of bacteria in duplicate. Medium without inoculation was distributed for negative controls. The plates were incubated in a microplate reader (Tecan GENios Plus, Männedorf, Switzerland) prewarmed to $37^{\circ} \mathrm{C}$ for $20 \mathrm{~h}$ at this temperature. Optical density at $492 \mathrm{~nm}$ was read every 20 min after orbital shaking for $10 \mathrm{~s}$. Each experiment was carried out in triplicate and the average data presented.

\section{RESULTS}

\section{Milk Yield and Lactose Concentration}

The dose of LPS applied in this experiment induced acute inflammation. Data on the severity of the induced immune reaction, such as SCC, rectal temperature, plasma cortisol concentration, and $\beta$ - $N$-acetyl-Dglucosaminidase (NAGase) activity in milk, using the same source and dose of LPS in Holstein cows of the ARO herd have been reported elsewhere (Lavon et al., 2008). Milk yields of all cows were $32.1 \pm 3.1 \mathrm{~L} / \mathrm{d}$ before the start of the experiment and did not differ between treatments at that time (Figure 1). No changes in MY were recorded in the control group ( $\mathrm{r}-$ and $\mathrm{c}-\mathrm{Con}$ ), suggesting that injection per se or environmental conditions during the experiment did not affect MY. The LPS challenge induced a significant transient decrease in milk yield in e-LPS quarters. The maximum decrease 
of approximately $30 \%$ was recorded at $24 \mathrm{~h}$ posttreatment, and MY recovery occurred after 4 to $5 \mathrm{~d}$, according to the continual automatic MY recording. Milk yield in c-LPS quarters decreased by about $20 \%$, but the effect was significantly milder compared with the effect on treated quarters and was apparent only at 24 $\mathrm{h}$ posttreatment (Figure 1). The LPS challenge induced a significant transient decrease in lactose concentration $(\sim 20 \%$ at $24 \mathrm{~h}$ posttreatment; Figure 2$)$ and lactose secretion ( $\sim 40 \%$ at $24 \mathrm{~h}$ posttreatment). Decreases of about 9 and $6 \%$ in lactose concentration at $24 \mathrm{~h}$ and $48 \mathrm{~h}$ posttreatment (Figure 2) and of about 14 and $11 \%$ in lactose secretion, respectively, were recorded in treatment c-LPS. No changes in lactose concentration were recorded in c-Con quarters.

\section{Secretion of Organic Acids (Lactate, Malate, and Citrate) and Urea}

In the experimental quarters, LPS challenge induced dramatic transient increases of 75 -fold (from 0.2 to 15 $\mathrm{m} M$ ) in L-lactate and 11-fold (from 0.45 to $5 \mathrm{mM}$ ) in malate concentrations at $24 \mathrm{~h}$ posttreatment (Figure 3, panels $\mathrm{A}$ and $\mathrm{B})$. At $48 \mathrm{~h}$ posttreatment, the concentration of L-lactate decreased to $\sim 7.5 \mathrm{~m} M$ and that of malate to $\sim 2.5 \mathrm{mM}$; both returned to pretreatment values at $72 \mathrm{~h}$ posttreatment. No significant changes in lactate and malate concentrations were recorded in treatments c-Con and c-LPS, indicating that the effect of LPS was restricted to the treated quarter (Figure 3, panels $\mathrm{A}$ and $\mathrm{B}$ ). D-Lactate concentration in all cows before the start of the experiment was within $100 \pm 90$

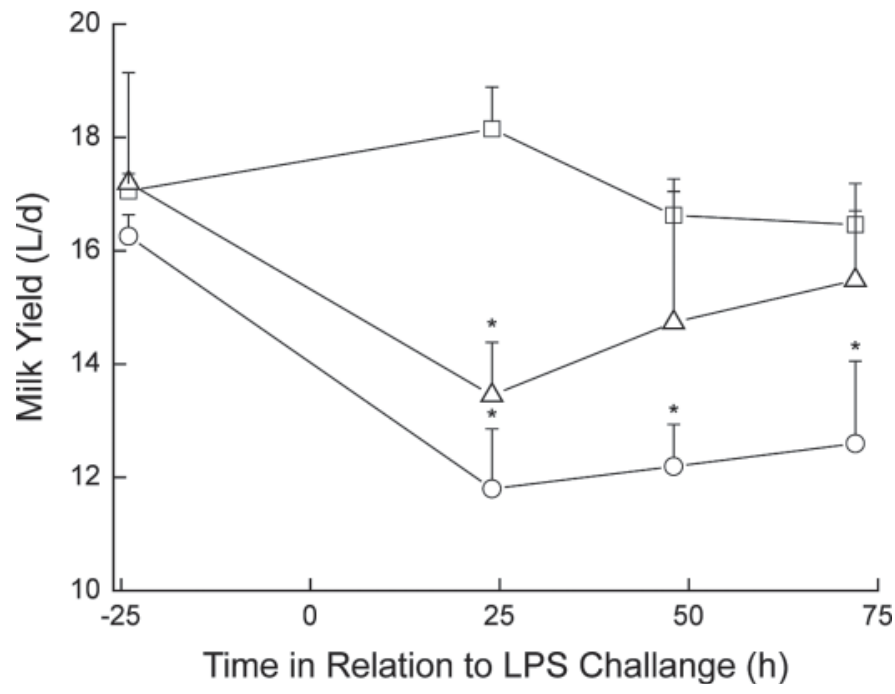

Figure 1. Effect of LPS on milk yield (L/d) in treated (circles), control-LPS (triangles), and control-control (squares) quarters. The results are presented as mean $\pm \mathrm{SD}$. Values marked by asterisk are significant at $P<0.001$ or lower.

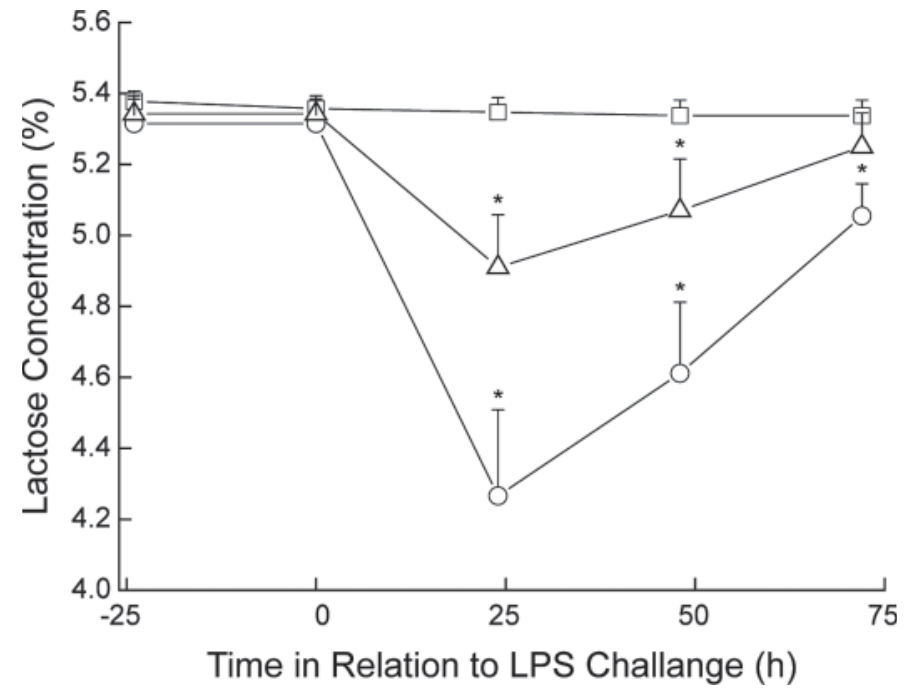

Figure 2. Effect of LPS on lactose (\%) concentration in treated (circles), control-LPS (triangles), and control-control (squares) quarters. Values marked by asterisk are significant at $P<0.001$ or lower.

$\mu M$, and its concentration was not affected by saline or LPS treatment.

The LPS challenge induced a dramatic transient decrease in citrate concentration (from 8.5 to $1.1 \mathrm{mM}$ ) at $24 \mathrm{~h}$ posttreatment, and the kinetics were inversely proportional to those of lactate and malate concentrations (Figure 3C).

The LPS challenge induced a transient increase of $18 \%$ in urea concentration $(P<0.05)$ at $24 \mathrm{~h}$ posttreatment in the treated quarter and c-LPS, which was reversed to a decrease of 17 and $22 \%(P<0.05)$ at 48 $\mathrm{h}$ and $72 \mathrm{~h}$ posttreatment, respectively. These responses were specific to LPS treatment as no changes in urea concentration were detected in c-Con (Figure 3D).

\section{Escherichia coli Growth in Broth Containing Lactose and Organic Acids}

Escherichia coli could not grow in broth depleted of carbohydrate (lactose) supplementation (Figure 4). It took approximately $10 \mathrm{~h}$ for the bacteria to adapt to the growing medium; after that, the culture reached confluency within $2 \mathrm{~h}$. Decreasing the lactose concentration to $3 \%$ extended the lag time before the growth phase by about $2 \mathrm{~h}$; after that, the culture reached the same confluency at a similar growth rate. Increasing lactate and malate concentrations in the broth to a level equivalent to that obtained at the peak of the response in the in vivo LPS challenge extended the lag time before the growth phase by about $2 \mathrm{~h}$ and decreased the number of bacteria at confluency without significant change in the growth rate (Figure 4). 

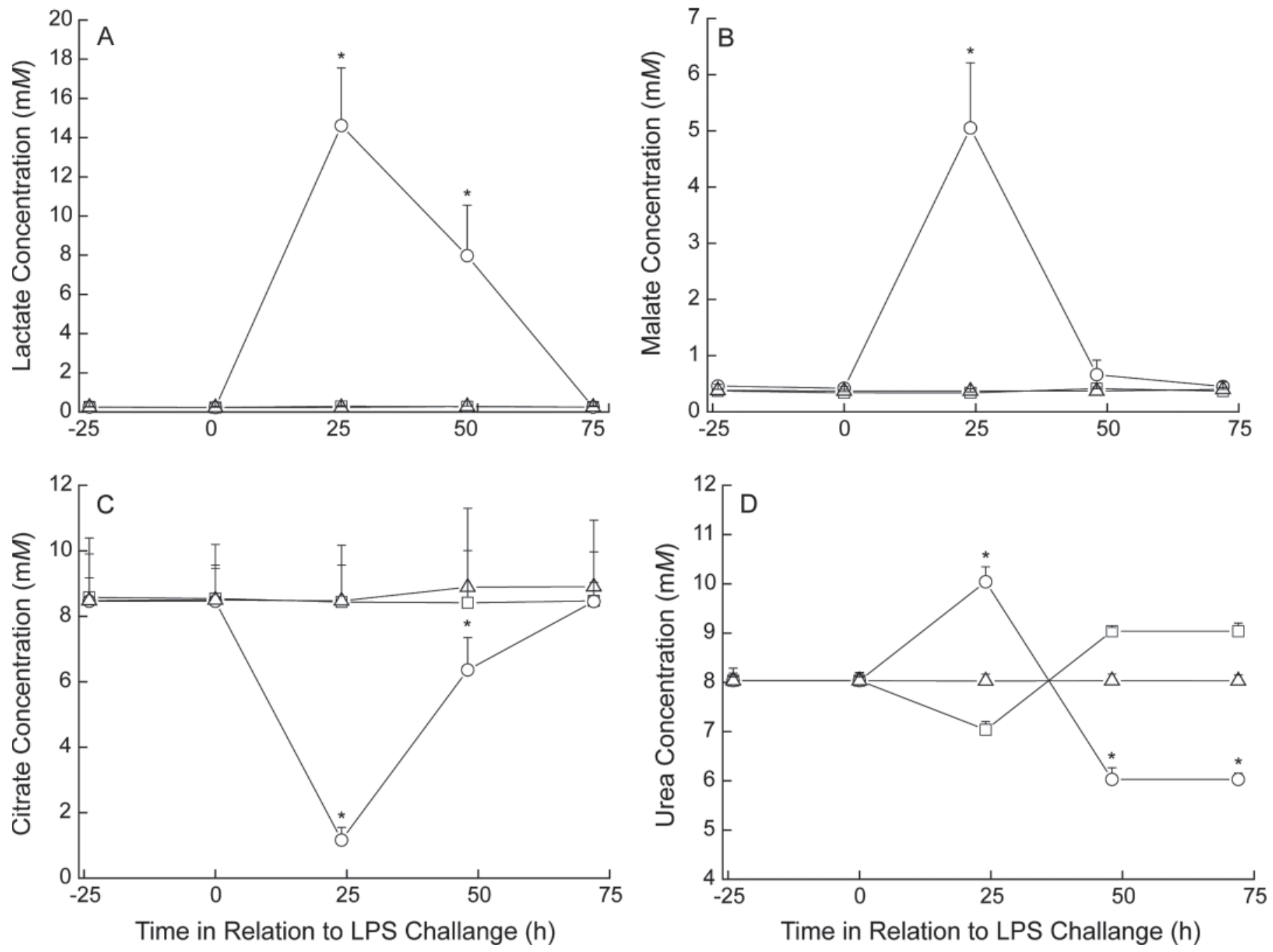

Figure 3. Effect of LPS on (A) lactate, (B) malate, (C) citrate, and (D) urea concentrations in treated (circles), control-LPS (triangles), and control-control (squares) quarters. The results are presented as mean \pm SD. Values marked by asterisk are significant at $P<0.05$ or lower.

\section{DISCUSSION}

Lactate is secreted from the cell cytosol through plasma transmembrane transporters (Ullah et al., 2006). Thus, the short-term, dramatic parallel changes in lactate and citrate concentrations in milk following LPS challenge should reflect a temporary shift of cell metabolism from chiefly respiratory-mitochondrial metabolism to cytosolic-anaerobic metabolism. This change, therefore, has to be associated with a drastic reduction (18-fold) in the ATP yield of mammary quarter epithelia and thus, supports our presupposition that induced decrease in mammary gland metabolism serves as a mechanism for decreasing milk synthesis and freeing metabolic resources to support the immune system.

Increase of the formation and secretion of lactate may be a consequence of an increase in the number or opening state of lactate transporters in the apical membrane of the epithelial cells, because its elimination from the cytosol will reduce its concentration in the cell cytosol and thus the negative-feedback regulatory effect on conversion of pyruvate to lactate by lactate dehydrogenase. Indeed, the number of lactate transporters is reported to increase during hypoxia (Ullah et al., 2006).

To the best of our knowledge, the substantial increase in malate secretion in response to LPS-induced inflammation, as found here, or under hypoxia, has not been described before. The increase in malate secretion during the shift to cytosolic metabolism can be explained by classical enzymatic cytosolic reactions of the intermediately metabolic repertoire:

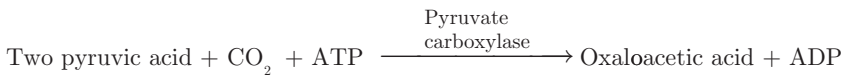




$$
\text { Oxaloacetic acid }+ \text { NADH } \stackrel{\begin{array}{l}
\text { Malic } \\
\text { dehydrogenase }
\end{array}}{\longrightarrow} \text { Malic acid }+\mathrm{NAD}^{+}
$$

The increased formation of $\mathrm{NAD}^{+}$due to the increased conversion of pyruvic acid to lactic and malic acids would be expected in turn to boost glycolysis, because $\mathrm{NAD}^{+}$, a byproduct in these reactions, is utilized by glyceraldehyde 3 -phosphate dehydrogenase, which plays a key role in glycolysis.

The hypoxic response, classically induced by low ambient oxygen, and the innate system that is forcefully activated by substances such as LPS are ancient stress responses. Recent publications have shown that these 2 systems are interrelated through their induced transcription factors (Nizet and Johnson, 2009). Lipopolysaccharide induces the nuclear factor- $\kappa \mathrm{B}$ signal pathway and in particular, an increase in the activity of the kinase IKK-b raises the level of the transcriptional regulator hypoxia-inducible factor-1 (HIF-1) in macrophages, and decreasing prolyl hydroxylase mRNA production in a toll-like receptor 4 (TLR4)-dependent fashion. Deletion of HIF-1 in macrophages was found to be protective against LPS-induced mortality (sepsis) and blocked the development of clinical markers, including hypotension and hypothermia (Peyssonnaux et al., 2007). However, one may also assume that the interrelationship between the common activation of these 2 systems may also have evolutionary advantages, which relates to improved resistance to infection and hypoxia challenges.

Hypoxia is generally considered a side effect of inflammation (Nizet and Johnson, 2009). The negative effect of LPS on mitochondrial function was demonstrated in cell culture model (Peyssonnaux et al., 2007). In the present study, we demonstrated for the first time that LPS challenge induces a shift toward glycolysis on the account of mitochondrial metabolism in the mammary gland under in vivo conditions. In turn, as discussed below, the change toward glycolysis has a major shortrange benefit in supporting the ability of the host to defend against aggressive bacterial invasion. Nevertheless, release of a large quantity of L-lactate from sites of sepsis and inflammation in animal models and human blood (Haji-Michael et al., 1999) supports the general validity of the hypothesis that lactate is more a product of inflammation induced by glycolysis than a marker of tissue hypoxia in sepsis.

Lactose is a nutritional substrate for pathogenic E. coli that invade the mammary gland (Blum et al., 2008), and many proteins involved in the metabolism of lactose and various amino acids were upregulated when E. coli was grown in a lactose-containing media (Burstein et al., 1964), including milk (Lippolis

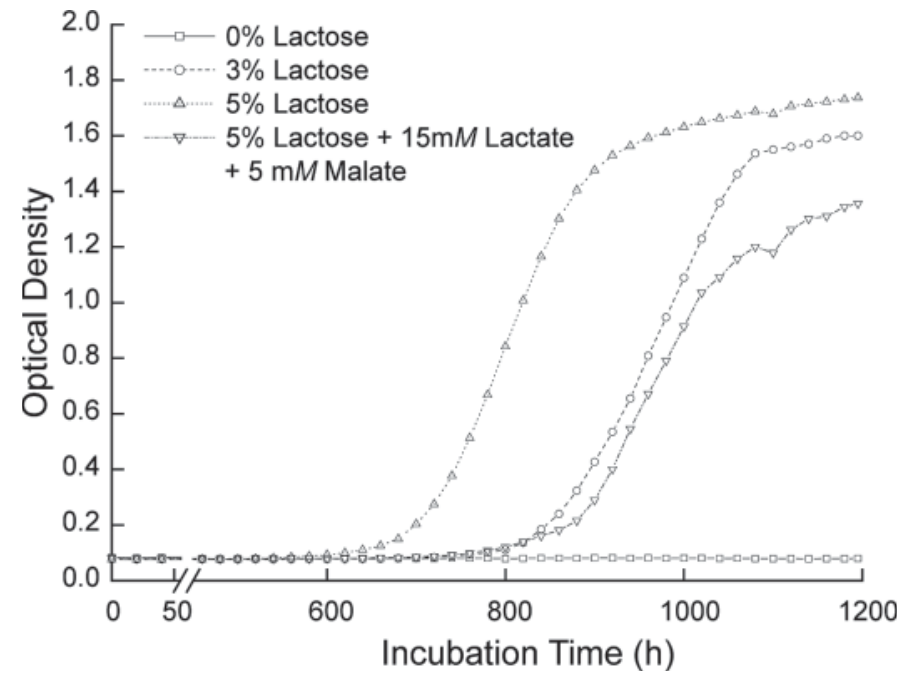

Figure 4. Effect of lactose concentration $(0,3$, and $5 \%)$ and a mixture of lactate $(15 \mathrm{mM})$ and malate $(5 \mathrm{mM})$ on the growth of pathogenic strain of Escherichia coli $\mathrm{P} 4$ in proteose peptone broth.

et al., 2009). In accordance, we showed that decreasing the lactose concentration to the level recorded in milk following LPS challenge delayed the growth of a pathogenic strain of $E$. coli. In food science, it is well established that organic acids, such as lactate and malate, have a preservation activity that prevents food contamination by bacteria (Laury et al., 2009; Raybaudi-Massilia et al., 2009). We have also shown that secretion of lactate and malate to extracellular fluids following LPS challenge reached a level that can significantly delay and decrease $E$. coli growth. The delay in reaching the stationary phase of growth rate is of potential physiological importance because the mammary gland is frequently emptied by suckling or milking. Thus, the present results suggest that a decrease in milk lactose concentration and an increase in lactate and malate concentrations are viable tools to fight against gram-negative bacterial infection.

Immune response requires a considerable proportion of mammalian energy and metabolite resources (Kominsky et al., 2010) and it is well established that undernutrition impairs the immune response (Raqib and Cravioto, 2009). Thus, the shift to cytosolic metabolism enabled a drastic reduction in the mammary gland whole metabolism and glucose utilization, as reflected in the acute reduction in milk yield and lactose secretion. This in turn would liberate valuable nutritional resources to support the immune response, such as the typical tremendous increase in the flow of SCC (mainly neutrophils) to the mammary gland during mastitis. The reduction in food intake is much smaller than the reduction in milk yield as clearly demonstrated 
by Waldron et al. (2006) under similar circumstances. Consistent with our results, LPS-induced experimental mastitis in dairy cows induced an increase in glucose production and plasma glucose concentration (Waldron et al., 2006). The maintenance of high glucose production despite the dramatic utilization of glucose by the mammary glands suggests that energy sparing induced by LPS is a protective mechanism, which enables an effective immune response during the early invasion of $E$. coli into the mammary gland (results of the current study; Waldron et al., 2006).

This hypothesis is indirectly supported by the ontogenesis in milk urea concentration following LPS challenge. Plasma urea concentration in general reflects systemic amino acid turnover (Harmeyer and Mertens, 1980). It is well established that urea diffuses rapidly through the alveolar epithelial cells, and its concentration in milk closely follows that in blood plasma (Oltner and Wiktorsson, 1983). The immediate increase in milk urea after LPS challenge most likely reflects the fightor-flight response (acute stress response; acute reaction to threats with a general discharge of the sympathetic nervous system), which is reflected in this case by rapid catabolism of proteins stored in the liver. On the other hand, the decrease in urea concentration to below pretrial levels most likely reflects the shift of mammary gland epithelial cells to anaerobic metabolism and the consequential large reduction in whole-body amino acid turnover. Similarly, in rats, systemic challenge with LPS upregulated in vivo urea synthesis during a moderate acute phase response; however, in the long term, LPS induced the opposite effect at the gene level and in urea synthesis (Nielsen et al., 2005).

The very rapid reversals in milk citrate and lactate concentrations to the prechallenge state indicate that the mammary gland restored very rapidly to normal aerobic metabolism. Inactivation of LPS in milk and other tissues is usually very rapid, which most likely explains the rapid return to normal metabolism. The continuation of milking also undoubtedly helps in reducing the concentration of LPS in the mammary gland.

In summary, LPS challenge induces acute conversion of the epithelial cells metabolism from principally mitochondrial-oxidative to principally cytosolic (glycolytic), which allows diversion of metabolic resources normally used to synthesize milk to support the immune system. In turn, the large increase in the concentration of lactate and malate in milk and the parallel reduction in lactose concentration are consistent with the concept that part of the defense mechanism of the mammary gland against invading organisms is a fundamental change in its internal milieu wherein conditions detrimental to bacterial proliferation are generated.

\section{REFERENCES}

Blum, S., E. D. Heller, O. Krifucks, S. Sela, O. Hammer-Muntz, and G. Lietner. 2008. Identification of a bovine mastitis Escherichia coli subset. Vet. Microbiol. 132:135-148.

Bramley, A. J. 1976. Variations in the susceptibility of lactating and non-lactating bovine udders to infection when infused with Escherichia coli. J. Dairy Res. 43:205-211.

Burstein, C., M. Cohn, A. Kepes, and J. Monod. 1964. Role du lactose et de ses produits metaboliques dans linduction de l'operon lactose chez Escherichia coli. Biochim. Biophys. Acta 95:634-639.

Cherepanov, G. G., A. Danfaer, and J. P. Cant. 2000. Simulation analysis of substrate utilization in the mammary gland of lactating cows. J. Dairy Res. 67:171-188.

Davis, S. R., V. C. Farr, C. G. Prosser, G. D. Nichols, S.-A. Turner, J. Lee, and A. L. Hart. 2004. Milk L-lactate concentration is increased during mastitis. J. Dairy Res. 71:175-181.

Haji-Michael, P. G., L. Ladriere, A. Sener, J. L. Vincent, and W. J. Malaisse. 1999. Leukocyte glycolysis and lactate output in animal sepsis and ex vivo human blood. Metab. Clin. Exp. 48:779-785.

Harmeyer, J., and H. Mertens. 1980. Aspects of urea metabolism in ruminants with reference to the goat. J. Dairy Sci. 63:1707-1728.

Heumann, D., and T. Roger. 2002. Initial responses to endotoxins and gram-negative bacteria. Clin. Chim. Acta 323:59-72.

Kadzere, C. T., M. R. Murphy, N. Silanikove, and E. Maltz. 2002 Heat stress in lactating dairy cows: A review. Livest. Prod. Sci. 77:59-91.

Kominsky, D. J., E. L. Campbell, and S. P. Colgan. 2010. Metabolic shifts in immunity and inflammation. J. Immunol. 184:4062-4068.

Laury, A. M., M. V. Alvarado, G. Nace, C. Z. Alvarado, J. C. Brooks, A. Echeverry, and M. M. Brashears. 2009. Validation of a lactic acid- and citric acid-based antimicrobial product for the reduction of Escherichia coli O157:H7 and Salmonella on beef tips and whole chicken carcasses. J. Food Prot. 72:2208-2211.

Lavon, Y., G. Leitner, T. Goshen, R. Braw-Tal, S. Jacoby, and D. Wolfenson. 2008. Exposure to endotoxin during estrus alters the timing of ovulation and hormonal concentrations in cows. Theriogenology 70:956-967.

Leitner, G., O. Krifucks, U. Merin, Y. Lavi, and N. Silanikove. 2006. Interactions between bacteria type, proteolysis of casein and physico-chemical properties of bovine milk. Int. Dairy J. 16:648-654.

Leitner, G., U. Merin, and N. Silanikove. 2011. Effects of glandular bacterial infection and stage of lactation on milk clotting parameters: comparison among cows, goats and sheep. Int. Dairy J. $21: 279-285$.

Lindmark-Mansson, H., C. Branning, G. Alden, and M. Paulsson. 2006. Relationship between somatic cell count, individual leukocyte populations and milk components in bovine udder quarter milk. Int. Dairy J. 16:717-727.

Linzell, J. L., T. B. Mepham, and M. Peaker. 1976. Secretion of citrate to milk. J. Physiol. 260:739-750.

Lippolis, J. D., B. O. Bayles, and T. A. Reinhardt. 2009. Proteomic changes in Escherichia coli when grown in fresh milk versus laboratory media. J. Proteome Res. 8:149-158.

Nielsen, S. S., T. Grofte, N. Tygstrup, and H. Vilstrup. 2005. Effect of lipopolysaccharide on in vivo and genetic regulation of rat urea synthesis. Liver Int. 25:177-183.

Nizet, V., and R. S. Johnson. 2009. Interdependence of hypoxic and innate immune response. Nat. Rev. Immunol. 9:609-617.

Oltner, R., and H. Wiktorsson. 1983. Urea concentration in milk and blood as influenced by feeding varying amount of protein and energy to dairy cows. Livest. Prod. Sci. 10:457-467.

Peyssonnaux, C., P. Cejudo-Martin, A. Doedens, A. S. Zinkernagel, R. S. Johnson, and V. Nizet. 2007. Cutting edge: Essential role of hypoxia inducible factor-1 alpha in development of lipopolysaccharide-induced sepsis. J. Immunol. 178:7516-7519.

Qiao, F., D. R. Trout, C. Xiao, and J. P. Cant. 2005. Kinetics of glucose transport and sequestration in lactating bovine mammary quarters measured in vivo with a paired indicator/nutrient dilution technique. J. Appl. Physiol. 99:799-806. 
Rainard, P., and C. Riollet. 2006. Innate immunity of the bovine mammary gland. Vet. Res. 37:369-400.

Raqib, R., and A. Cravioto. 2009. Nutrition, immunology, and genetics: Future perspectives. Nutr. Rev. 67:S227-S236.

Raybaudi-Massilia, R. M., J. Mosqueda-Melgar, and O. Martin-Belloso. 2009. Antimicrobial activity of malic acid against Listeria monocytogenes, Salmonella enteritidis and Escherichia coli O157:H7 in apple, pear and melon juices. Food Contr. 20:105-112.

SAS Institute. 2002. JMP Statistics and Graphics Guide, Version 5. SAS Institute Inc., Cary, NC.

Shamay, A., F. Shapiro, G. Leitner, and N. Silanikove. 2003. Infusions of casein hydrolyzates into the mammary gland disrupt tight junction integrity and induce involution in cows. J. Dairy Sci. $86: 1250-1258$

Shamay, A., F. Shapiro, S. J. Mabjeesh, and N. Silanikove. 2002. Casein-derived phosphopeptides disrupt tight junction integrity, and precipitously dry up milk secretion in goats. Life Sci. 70:27072719.

Shapiro, F., and N. Silanikove. 2010. Rapid and accurate determination of D- and L-lactate, lactose and galactose by enzymatic reactions coupled to formation of a fluorochromophore: Applications in food quality control. Food Chem. 119:829-833.

Shapiro, F., and N. Silanikove. 2011. Rapid and accurate determination of malate, citrate, pyruvate and oxaloacetate by enzymatic reactions coupled to formation of a fluorochromophore: Application in colorful juices and fermentable food (yogurt, wine) analysis. Food Chem. 129:608-613.

Silanikove, N. 1994. The struggle to maintain hydration and osmoregulation in animals experiencing severe dehydration and rapid rehydration: The story of ruminants. Exp. Physiol. 79:281-300.
Silanikove, N. 2000. Effects of heat stress on the welfare of extensively managed domestic ruminants. Livest. Prod. Sci. 67:1-18.

Silanikove, N., U. Merin, and G. Leitner. 2006. Physiological role of indigenous milk enzymes: An overview of an evolving picture. Int. Dairy J. 16:533-545.

Silanikove, N., A. Shamay, D. Shinder, and A. Moran. 2000. Stress down regulates milk yield in cows by plasmin induced $\beta$-casein product that blocks $\mathrm{K}^{+}$channels on the apical membranes. Life Sci. 67:2201-2212.

Silanikove, N., and F. Shapiro. 2007. Distribution of xanthine oxidase and xanthine dehydrogenase activity in bovine milk: Physiological and technological implications. Int. Dairy J. 17:1188-1194.

Silanikove, N., F. Shapiro, and D. Shinder. 2009. Acute heat stress brings down milk secretion in dairy cows by up-regulating the activity of the milk-borne negative feedback regulatory system. BMC Physiol. 9:13.

Ullah, M. S., A. J. Davies, and A. P. Halestrap. 2006. The plasma membrane lactate transporter MCT4, but not MCT1, is up-regulated by hypoxia through a HIF-1 alpha-dependent mechanism. J. Biol. Chem. 281:9030-9037.

Waldron, M. R., A. E. Kulick, A. W. Bell, and T. R. Overton. 2006. Acute experimental mastitis is not causal toward the development of energy-related metabolic disorders in early postpartum dairy cows. J. Dairy Sci. 89:596-610.

Zulak, I. M., and T. W. Keenan. 1983. Citrate accumulation by Golgi apparatus-rich fraction from lactating bovine mammary gland. Int. J. Biochem. 15:747-750. 